\title{
Novel insulation panels development from multilayered coir short and long fiber reinforced phenol formaldehyde polymeric biocomposites
}

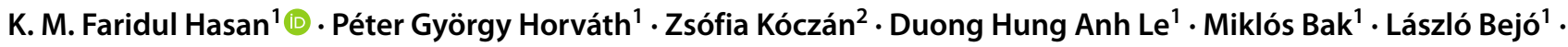 \\ Tibor Alpár ${ }^{1}$
}

Received: 20 July 2021 / Accepted: 3 November 2021 / Published online: 18 November 2021

(c) The Author(s) 2021

\begin{abstract}
This study investigated about the developments of insulation panels from multilayered coir long and short fiber reinforced phenol formaldehyde polymeric (PF) resin. The lengths of coir long fibers (CLF) were within $3 \mathrm{~mm}$, whereas the short fibers (CSF) ranged from $0.1 \mathrm{~mm}$ to $1.25 \mathrm{~mm}$. Four composite panels of $360,680,800$, and $1000 \mathrm{~kg} / \mathrm{m}^{3}$ densities were developed by employing hot pressing technology. The thermal conductivity, microstructural, mechanical, and physical properties of the composite panels were investigated. Perceived thermal conductivity values ranged within $0.046280(0.000494)$ to 0.062400 (0.001146) $\mathrm{Wm}^{-1} \mathrm{k}^{-1}$ of the composites demonstrating superior insulation properties. Moreover, the current study also found that mechanical and thermal properties showed improvement with the increase of density. Low-density fiberboards had the lowest performances compared to high-density composite panels, with the exception of the $1000 \mathrm{~kg} / \mathrm{m}^{3} \mathrm{density}$, in which fiber agglomeration occurred. Furthermore, all the developed composite panels display superior potentiality for use as effective insulation materials. The FTIR (Fourier transform infrared spectroscopy) analysis also shows an efficient bonding between the cellulosic coir materials and PF resin. The overall characteristics of the composite panels, especially medium fiberboard, show prominent potential for industrial production units by fulfilling the consumer requirements.
\end{abstract}

Keyword Coir fiber $\cdot$ Biocomposites $\cdot$ Mechanical performance $\cdot$ Physical properties $\cdot$ Sustainable products

\section{Introduction}

The increasing awareness of worldwide environmental pollution has increased the importance of bio-based polymeric composite panels. The use of naturally derived fiber materials as potential reinforcements could facilitate the composite sector with enhanced sustainability [1-9]. Among other natural fibers, coir is a crucial renewable fiber material. Coir materials are derived from coconut husks and are produced extensively in Southeast Asian countries. Much research on

K. M. Faridul Hasan

faridulwtu@outlook.com

Tibor Alpár

alpar.tibor@uni-sopron.hu

1 Simonyi Károly Faculty of Engineering, University of Sopron, Sopron, Hungary

2 Paper Research Institute, Simonyi Károly Faculty of Engineering, University of Sopron, Sopron, Hungary long coir fiber reinforced composites has been conducted. The bulk of the research focuses on coir reinforced with different thermoplastic (like polypropylene (PP), polylactic acid (PLA), PHBV (3-hydroxybutyrate-co-3-hydroxyvalerate), polybutylene succinate (PBS)) [10-14], thermosetting (like epoxy) $[15,16]$, and cementitious reagents like OPC (Ordinary Portland cement) [17-20]. Sometimes, nanoparticles (NPs) are also utilized to develop the hybrid nanocomposites in order to improve the performances [21-23]. Additionally, NPs are not yet widely implemented for industrial production. Therefore, it is tried to innovate the feasibility of multilayered coir material reinforced PF composites having improved insulation properties. However, research on coir chips, a byproduct generated during coir fiber processing, is not extensive, particularly not on chips with improved mechanical properties. In our previous study, we reported on the development of coir chips (without extracting into fiber) along with long coir materials reinforced with MUF (melamine-urea-formaldehyde) [24]. However, the internal bonding strengths were less than $0.5 \mathrm{MPa}$, which, depending 
on density, is the standard for fiber composite panels. The reason for this may be the lowered compatibility between the coconut chips and MUF polymers although the coir materials were pretreated before the fabrications. However, if the chips are extracted into fiber forms, they could provide better reinforcement effects in the composite system, which may increase the fiber to polymer adhesions. Furthermore, the changes in polymeric materials could also provide better reinforcement effects. Coir fibers (short fiber extracted from chips and long fibers directly from coconut husks) reinforced with another potential thermosetting polymers such as PF have not been investigated yet. To our knowledge, this fabrication protocol has not been studied yet. The process involves employing hot-press technology, which provided excellent reinforcement effects with improved internal bonding strengths of higher than $0.5 \mathrm{MPa}$ in the case of medium density panels.

As Table 1 shows, Coir fiber is a prominent lignocellulosic material possessing significant lignin $(48.3 \pm 1.9 \%)$, cellulose $(43.4 \pm 1.2 \%)$, and some other polymers like hemicellulose and ash. Chemically, coir fiber contains a higher lignin proportion than cellulose when compared to other natural fibers [25]. Previously, coconut husks were used extensively for culinary purposes, following the collection of liquid endosperm and copra [26]. The disposal of coconut husks and entire dried coconuts had become a considerable environmental threat as both the husks and the entire coconuts could remain in the environment for extended periods of time before decomposing. The utilization of coconut husks as fiber materials mitigates such challenges and ecological hazards. However, coconut husks could have extensive potential in biocomposite productions. In this regard, science and industry are investing significant attention into utilizing coir materials in gainful ways [15, 27-30]. For some time, thermoset polymers have played a considerable role in developing fiber reinforced composite products [31]. Thermoset polymers facilitate the composite materials with better mechanical, chemical, and dimensional stability as well as thermal performances by creating a "cross-link" with the polymers [32]. Among different thermosetting polymers,

Table 1 Characteristics of coir fibers [40]

\begin{tabular}{ll}
\hline Constituent polymers & Coir fiber [41] \\
\hline Cellulose & $43.4 \pm 1.2$ \\
Hemicellulose & $4.0 \pm 0.003$ \\
Lignin & $48.3 \pm 1.9$ \\
Ash & $3.5 \pm 0.2$ \\
Moisture content & $10.2 \pm 0.5$ \\
Crystallinity & 44 \\
Elongation (\%) & $8.0 \pm 1.0$ \\
Tensile strength (MPa) & $120 \pm 5$ \\
\hline
\end{tabular}

polyester [33, 34], epoxy [35, 36], MUF [37], and PF [38] are used largely for natural fiber reinforced composite production. PF resin shows higher stiffness, chemical resistance, and excellent insulation properties [39]. In the circumstances mentioned above, $\mathrm{PF}$ resin is employed for developing trilayered biocomposite panels through reinforcement with coir materials for insulation performances.

The developed products from coir fibers retain versatile potentiality for being used as the low as insulation material for the housing and construction sector and demanded green consumer products. Moreover, the automotive industries, airspace companies, and different sporting good manufacturers are using coir fiber reinforced composites too. Furthermore, coir fiber reinforced panels are getting also much attention by the composite community. However, the utilization of coir chips extracted into CSF materials with CLF (Fig. 1) could be an interesting area of research, one that would facilitate manufacturers with a new dimension of potential composite materials. Moreover, thermo-mechanical performances are also dependent on the density of composite materials, which was a main focus for this research. Manufacturers from a variety of industries utilize biocomposite materials with varying densities in products including but not limited to automobiles, furniture, insulation, etc. With the advancements of science and technology, demands on sustainable insulation products from natural fibers reinforced with polymeric resin is also getting attentions. Moreover, research studies on coir fibers extracted from coconut chipreinforced $\mathrm{PF}$ resin multi-layered composite panels have not been investigated yet especially for insulation materials. The current study examines the reinforcement effects of different densities to provide more options that are viable for manufacturers. Such a novel fabrication technology could provide superior thermo-mechanical performances on the developed composite panels which are prerequisite to the panel industry.

\section{Materials and methods}

\section{Materials}

For the purposes of this research study, coconut (cocos nucifera) chips and CLF materials were collected from Pro Horto Ltd., (Szentes, Hungary). Prior to biocomposite fabrication, the coir chips were defibrated employing a defibrating machine (VZ 23,412 model, Dinamo Budapest, Hungary). The CLF were cut into nearly $3 \mathrm{~mm}$ lengths. Chemco a. s. Co., Slovakia generously supplied the chemical reagent $\mathrm{PF}$ required for the research. The characteristics of PF are as follows: reddish brown in appearance, viscose (240 to 380 mPa.s) and liquid, dry matter content (48), density $1210 \pm 20 \mathrm{~kg} / \mathrm{m}^{3}$, alkaline $\mathrm{pH}$ ranged from 10 to 12 . 


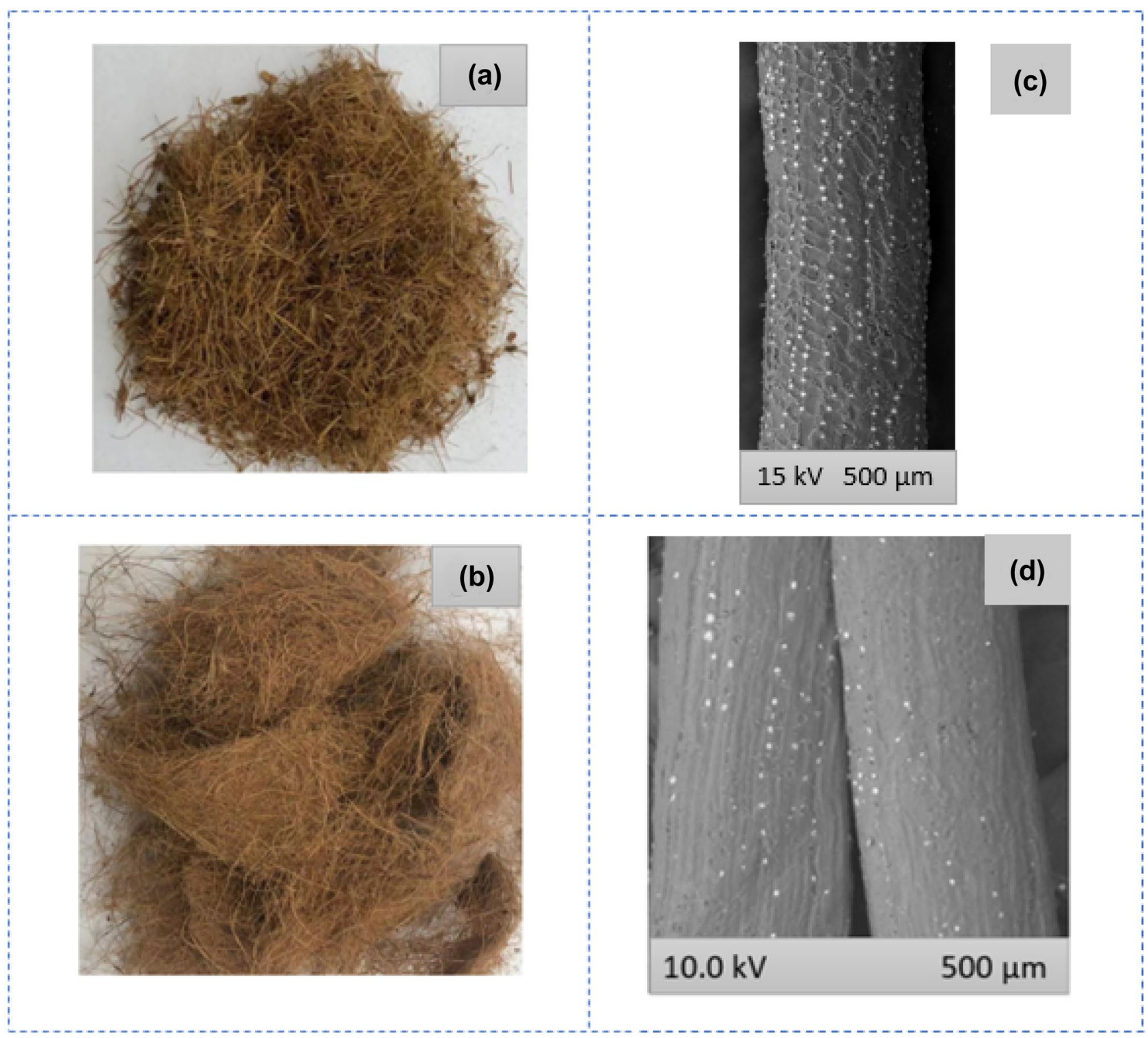

Fig. 1 Physical and morphological photographs of coir fibers: (a) Physical photographs of short coir fibers extracted from chips; (b) Physical photographs of long coir fibers; (c) SEM photographs of coir short fibers; (d) SEM photographs of coir long fibers

\section{Methods}

\section{Coir fiber preparation from coconut chips and sieving}

Coconut husks were carefully defibrated by adjusting the distance between the grinders and grain to protect against fiber damage during processing. The defibrated coir fibers were sieved with a sieve analyzer (ANALYSETTE 3Pro, Germany) to produce uniform fibers before biocomposite panel fabrication. Our previous studies provide detailed descriptions of similar sieving protocols for different natural fibers [24, 42]. For this test, $100 \mathrm{~g}$ coir fibers were randomly selected from the defibrated materials. The sieved lengths of CSF were within 0.1-1.25 mm (Fig. 2). The maximum fibers (42.7\%) were of $1.25 \mathrm{~mm}$ lengths, whereas $26.6 \%$ of fibers possessed $0.355 \mathrm{~mm}, 22.5 \%$ of fibers 0.1 , and $7.4 \%$ of fibers $0.8 \mathrm{~mm}$ lengths. The defibrated fibers exhibited diversified fiber lengths. Conversely, CLFs were cut into nearly 3 mm length before the composites fabrication.

\section{Production of biocomposite panels}

Before starting biocomposite panel fabrication, CSF and CLF moisture contents were measured. Our previous studies discuss the detailed measurement procedures [24, 43]. 

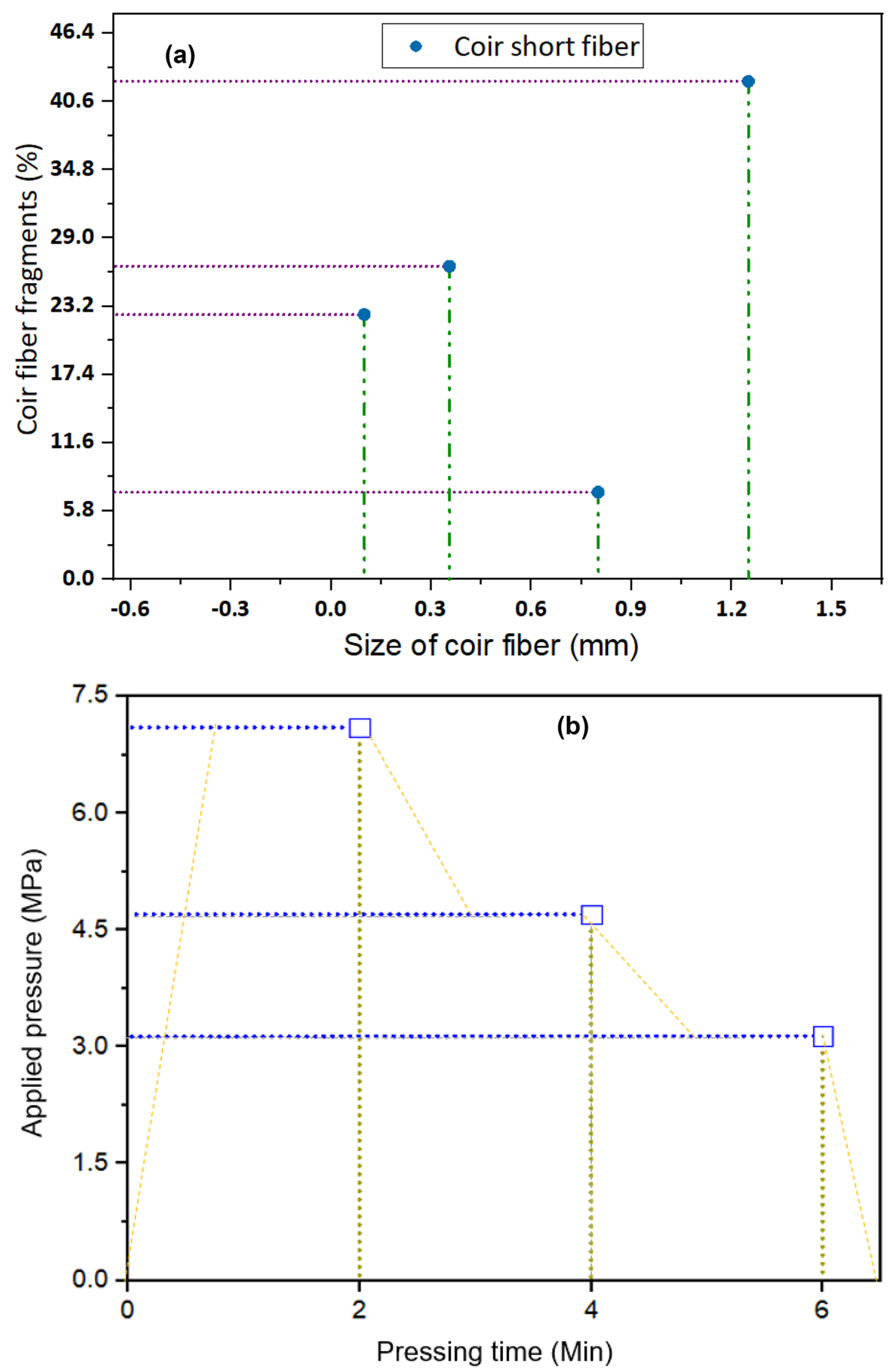

Fig. 2 (a) Size distribution of CSF and (b) Pressure versus time curve used for biocomposites manufacturing from CSF and CLF reinforced with PF resin 


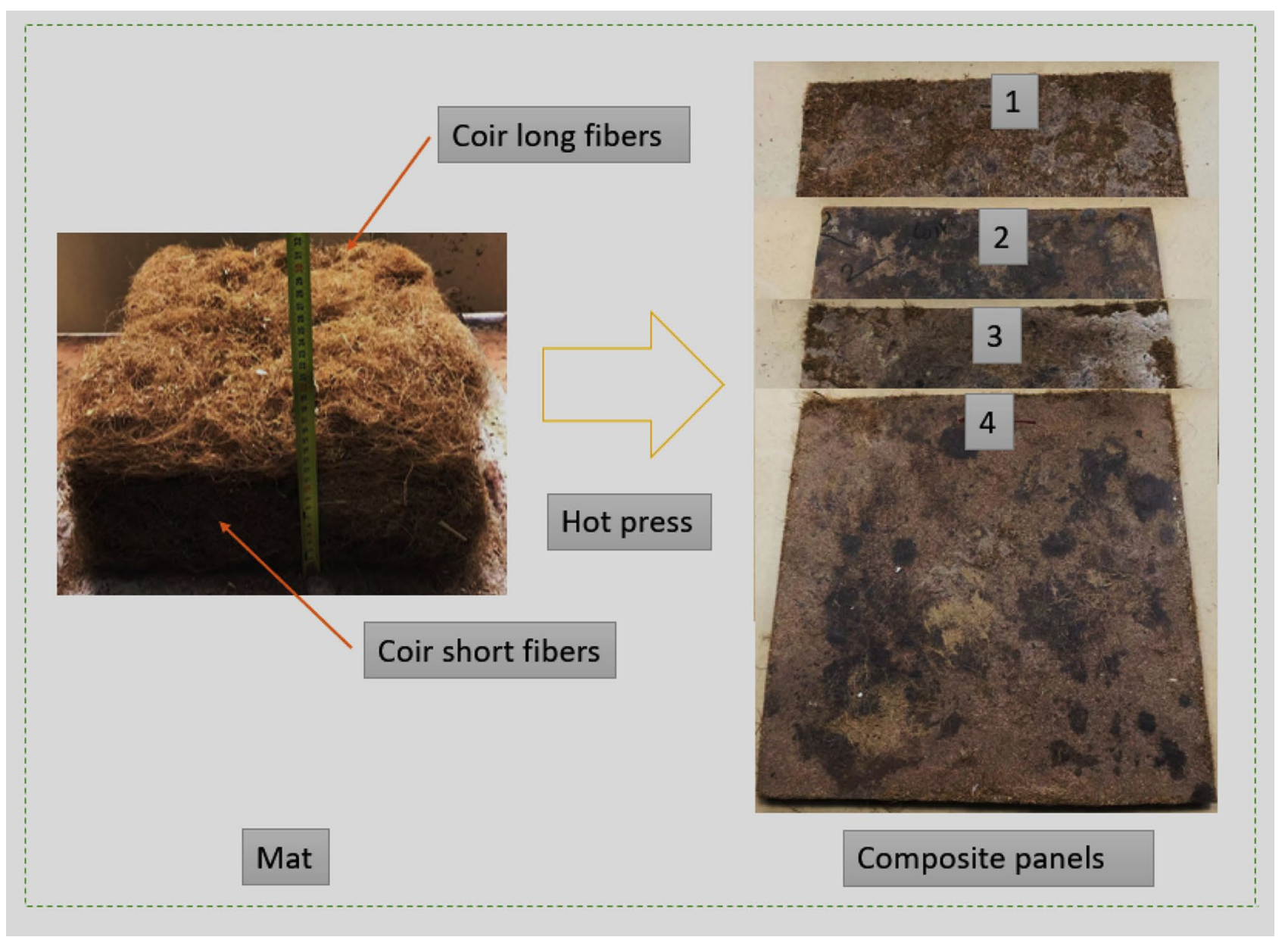

Fig. 3 Schematic physical photographs of produced composite panels from CSF and CLF material reinforced with PF resin

The investigated CSF moisture contents were $3.08 \%$, while for CLF it was $3.18 \%$. Furthermore, PF moisture content was nearly $34 \%$ and mat was around $10 \%$ (considered for recipe formulation). The CSF, CLF, and PF were measured proportionately as per recipe (Table 2). The proportion of CSF was $70.2 \%$, CLF $17.8 \%$, and PF adhesive $10 \%$. However, the actual quantity of materials varied depending on different densities of the composite panels $(360,860,800$, and $\left.1000 \mathrm{~kg} / \mathrm{m}^{3}\right)$. C@SL1 is recipe 1 , whereas recipe 2 is C@SL2, recipe 3 is C@SL3, and recipe 4, C@SL4. The

Table 2 Experimental design for CSF and CLF material reinforced PF biocomposite production

\begin{tabular}{llllll}
\hline $\begin{array}{l}\text { Composite } \\
\text { materials }\end{array}$ & $\begin{array}{l}\text { CSF } \\
\text { (proportion) }\end{array}$ & $\begin{array}{l}\text { U-CLF } \\
\text { (proportion) }\end{array}$ & $\begin{array}{l}\text { L-CLF } \\
\text { (proportion) }\end{array}$ & $\begin{array}{l}\text { A } \\
\text { (proportion) }\end{array}$ & $\begin{array}{l}\mathrm{ND} \\
\left(\mathrm{kg} / \mathrm{m}^{3}\right)\end{array}$ \\
\hline C@ SL1 & 80 & 5 & 5 & 10 & 360 \\
C@ SL2 & 80 & 5 & 5 & 10 & 680 \\
C@SL3 & 80 & 5 & 5 & 10 & 800 \\
C@SL4 & 80 & 5 & 5 & 10 & 1000 \\
\hline
\end{tabular}

*CSF- Coir short fiber, U-CLF- Coir long fiber (Upper), L-CLFCoir long fiber (Lower), and A- Adhesive, ND-Nominal density dimensions $\left(400 \times 400 \times 8 \mathrm{~mm}^{3}\right)$ of the panels were also kept uniform. Initially, CSF and PF were mixed evenly by using a rotating drum in the laboratory. The adhesive was continuously sprayed with a spray gun until the completion of measured PF. An extra $10 \%$ of materials were taken in order to ensure that exact quantity would remain after the mixing of adhesive and fibers. Finally, the mixed materials were measured again (at the middle) for every composite panel, and then placed inside a wooden frame of $400 \times 400$ $\mathrm{mm}^{2}$ over Teflon paper in the steel plate. However, CLF materials were positioned in the upper and lower parts of the mat (Fig. 3). When the materials were in place, the mat was pressed using another wooden lid. Both the wooden lids and framed boxes were removed, and another steel plate was placed over the mat after two $8 \mathrm{~mm}$ steel rods were positioned at the two sides. Finally, the mat in the steel plates was transferred to a hot press machine. The mat was pressed under 7.1, 4.7, and 3.2 MPa pressure; the temperature was $140{ }^{\circ} \mathrm{C}$. The composite panels were pressed for a duration of $40 \mathrm{~s}$ (15 s for every $1 \mathrm{~mm}$ thickness) in three consecutive stages to ensure uniform release of the pressure from the panels. When the 

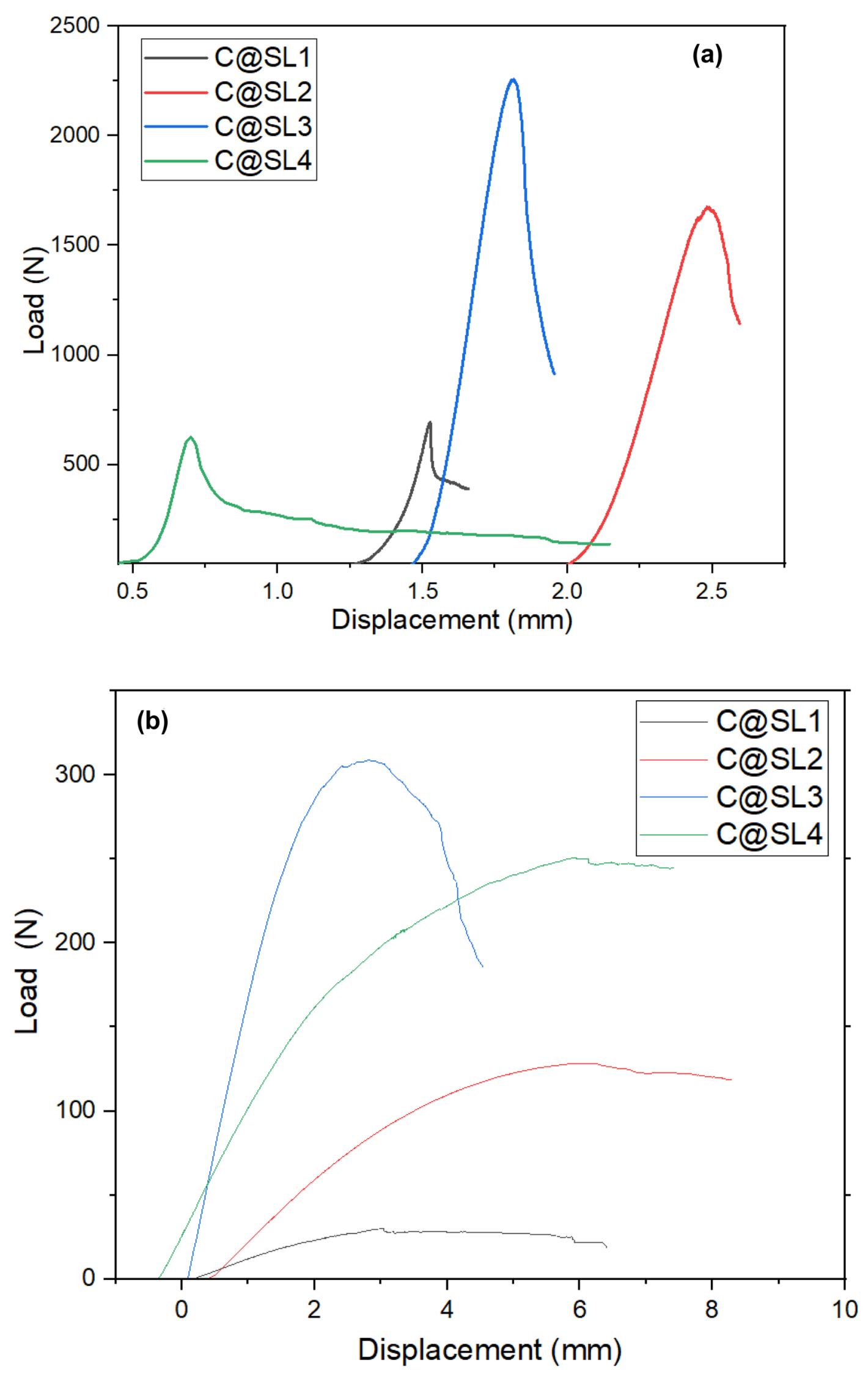
४Fig. 4 Load versus displacement curves of produced composite materials from CSF and CLF material reinforced with PF resin: (a) internal bonding strength and (b) flexural properties

pressing period was completed, the machine was cooled down to normal temperature (around $25^{\circ} \mathrm{C}$ ) and the produced panel was removed from the machine. All the panels were produced accordingly and cured for 1 day in ambient laboratory conditions.

\section{Characterizations}

CSF and CLF moisture contents were investigated using a Kern ULB 50-3 N moisture analyzer manufactured by KERN AND SOHN GmbH Co., Germany, according to the procedures of standard EN 322:1993. Thermal conductivity was characterized as per standard procedures of MSZ EN ISO 10456. Our previous studies provided detailed discussions of different cellulosic material reinforced composites $[24,44]$. The mechanical properties, in terms of flexural performances and internal bonding strengths, were tested using Instron testing equipment (4208, USA). The testing standard for flexural properties followed the EN 310 standard, whereas the EN 319 standard was followed for internal bonding strengths. The crosshead movement speed for flexural properties testing was $5.0 \mathrm{~mm} / \mathrm{min}$ and internal bonding strength was $0.8 \mathrm{~mm} / \mathrm{min}$. The test specimens were prepared using a circular saw (DCS570N XJ model, Pennsylvania, USA). The morphological characteristics were studied employing a scanning electron microscope (SEM, S 3400 N, High Technologies Co., Ltd., Hitachi, Japan) at different magnifications and $10.0 \mathrm{kV}$ voltage. The chemical components present in the fabricated composite panels were also investigated in terms of SEM mediated EDX analysis. Moreover, the chemical bonding of the panels also performed by FT/IR-6300 equipment (Jasco, Japan) within the wavenumber 4000 to $400 \mathrm{~cm}^{-1}$.

\section{Results and discussion}

\section{Mechanical properties of the developed biocomposite panels}

Figure 4a illustrates the typical load versus the displacement curves of the developed composite panels from CSF and CLF reinforced with PF resin are illustrated in reference to internal bonding strength properties. All the composite samples showed an elastic behavior until they reached to their maximum peak, which was followed by post-peak softening characteristics as well, especially for the coir fiber inclusion in the composite system [45]. However, the explicit effects of density on the composite materials are clearly visible. After a certain density level, a difference evolved, especially in composite panel 4 . This may be because the fibers agglomerated at higher density. Therefore, a sudden, declined peak is observed after composite panel 1, 2, and 3 . The highest peak for composite panel 1 was at nearly $692 \mathrm{~N}$. For composite panel 2, this figure was at 1674 N. Composite panels 3 and 4 had $2191 \mathrm{~N}$ and $626 \mathrm{~N}$, respectively. The load continued with the extended delaminations until the total failure of the test specimens occurred. Conversely, similar characteristics were also observed for flexural properties load versus displacement characteristics Fig. 4b. The maximum load required to reach the highest peak for the composite panels were as follows: composite panel 1 is at nearly $29.78 \mathrm{~N}$, composite panel 2 at $128 \mathrm{~N}$, composite panel 3 at $309 \mathrm{~N}$, and composite panel 4 at $250 \mathrm{~N}$. However, composite panel 4 showed higher resistance against load compared to composite panels 1 and 2. Nevertheless, composite panel 3 still displayed the highest loading pattern, whereas the density was $800 \mathrm{~N}$.

The similarity of the trends is also reflected in the perceived internal bonding strength and flexural properties tabulated in Table 3. Composite panel 1 (entailing lowest density) produced the lowest value of internal bonding strength at $0.185(0.085) \mathrm{MPa}$. Composite panel 3 had the highest value at $0.74(0.099) \mathrm{MPa}$. Composite panel 2 and 4 provided $0.70(0.076)$ and $0.15(0.03) \mathrm{MPa}$ internal bonding strengths. However, composite panel 1 presented $30 \%$ less internal bonding strength than composite panel 3 and $27.8 \%$ less than composite panel 2 . However, the agglomeration results in a deteriorated internal bonding strength for composite panel 4; hence, even composite panel 1 displayed $18.9 \%$ higher strength compared to composite panel 4 . On the other hand, the density difference between composite panel 2 and 3 is not as high (both are medium density fiberboards); thus, they also displayed very little difference when it came to mechanical properties. Composite panel 3 showed $5.4 \%$ higher internal bonding strength compared to composite panel 2. Likewise, nearly similar results were also found for flexural strength and modulus (Table 3 ). The highest flexural properties were in C@SL3 15.47 (0.41) MPa whereas

Table 3 Mechanical properties of produced composites from CSF and CLF materials reinforced with PF resin

\begin{tabular}{|c|c|c|c|c|}
\hline $\mathrm{BC}$ panel & $\begin{array}{l}\mathrm{D} \\
\left(\mathrm{kg} / \mathrm{m}^{3}\right)\end{array}$ & $\begin{array}{l}\text { MOR } \\
(\mathrm{MPa})\end{array}$ & $\begin{array}{l}\mathrm{MOE} \\
(\mathrm{GPa})\end{array}$ & $\begin{array}{l}\text { IBS } \\
(\mathrm{MPa})\end{array}$ \\
\hline C@SL1 & $\begin{array}{l}453.30 \\
(13.31)\end{array}$ & $\begin{array}{l}1.76 \\
(0.67)\end{array}$ & $\begin{array}{l}0.64 \\
(0.008)\end{array}$ & $0.185(0.085)$ \\
\hline C@SL2 & $\begin{array}{l}648.03 \\
(52.53)\end{array}$ & $\begin{array}{l}9.67 \\
(0.99)\end{array}$ & $\begin{array}{l}1.62 \\
(0.17)\end{array}$ & $0.70(0.076)$ \\
\hline C@SL3 & $\begin{array}{l}894.48 \\
(75.75)\end{array}$ & $\begin{array}{l}15.47 \\
(0.41)\end{array}$ & $\begin{array}{l}3.58 \\
(0.38)\end{array}$ & $0.74(0.099)$ \\
\hline C@SL4 & $\begin{array}{l}978.62 \\
(79.12)\end{array}$ & $\begin{array}{l}12.88 \\
(0.98)\end{array}$ & $\begin{array}{l}3.6 \\
(0.31)\end{array}$ & $0.15(0.03)$ \\
\hline
\end{tabular}


C@SL4 12.88 (0.98) MPa provided higher flexural strengths than C@SL1 and C@SL2. However, the flexural modulus exhibited an increasing trend with the rise of actual density from low to high. Interestingly, the results agree with other studies examining coir fiber reinforced with different polymers like epoxy and polyester composites [46, 47]. The actual densities obtained for different composite panels after fabrication were 453.30 (13.31), 648.03 (52.53), 894.48 (75.75), and $978.62(79.12) \mathrm{kg} / \mathrm{m}^{3}$, while the nominal densities were $360,680,800$, and $1000 \mathrm{~kg} / \mathrm{m}^{3}$, respectively. The density differences possibly occurred due to errors in the fabrication processes and testing sample preparations. In summary, it can be concluded that the density of the composite panels significantly influence the mechanical performances.

\section{Morphological properties of the developed biocomposite panels}

The surface morphology of the fractured surfaces of CSF and CLF material reinforced PF biocomposite panels are shown in Fig. 5. The investigation on fractured surfaces of the biocomposite panels determine the reinforcement effects on the composite system in terms of fiber pull out. The fracture portions of the matrix clearly exhibit the presence of homogeneous distributions of coir materials in the composite materials.
Fig. 6 EDX spectrum of manufactured composite materials from CSF and CLF material reinforced with PF resin (a) control coir material, (b)C@SL1, (c)C@SL2, (d) C@SL3, and (e) C@SL4

The tearing of fibers demonstrates a strong fiber to matrix bonding, which is also reflected in their improved mechanical performances. After the reinforcement, surfaces of coir fibers become rougher, resulting in better fiber-to-matrix interactions [48]. Moreover, the fiber to polymer gap did not appear significantly, likely because of the stronger interactions between the fiber and the polymer leading to less void generation during composite formation [49]. Stronger chemical bonding is also reflected in the FTIR and EDX investigations. The overall discussions signify strong and successful reinforcement effects in the composite systems.

\section{EDX characterization of developed biocomposite panels}

The elemental quantity of control coir fiber and associated PF bonded polymeric composites were examined further. $\mathrm{C}$ and $\mathrm{O}$ are the main chemical components of natural fibers, which is also shown in Fig. 6. However, when the coir fibers were reinforced with PF resins, another chemical element, $\mathrm{N}$, is significantly detected in the composite system, in

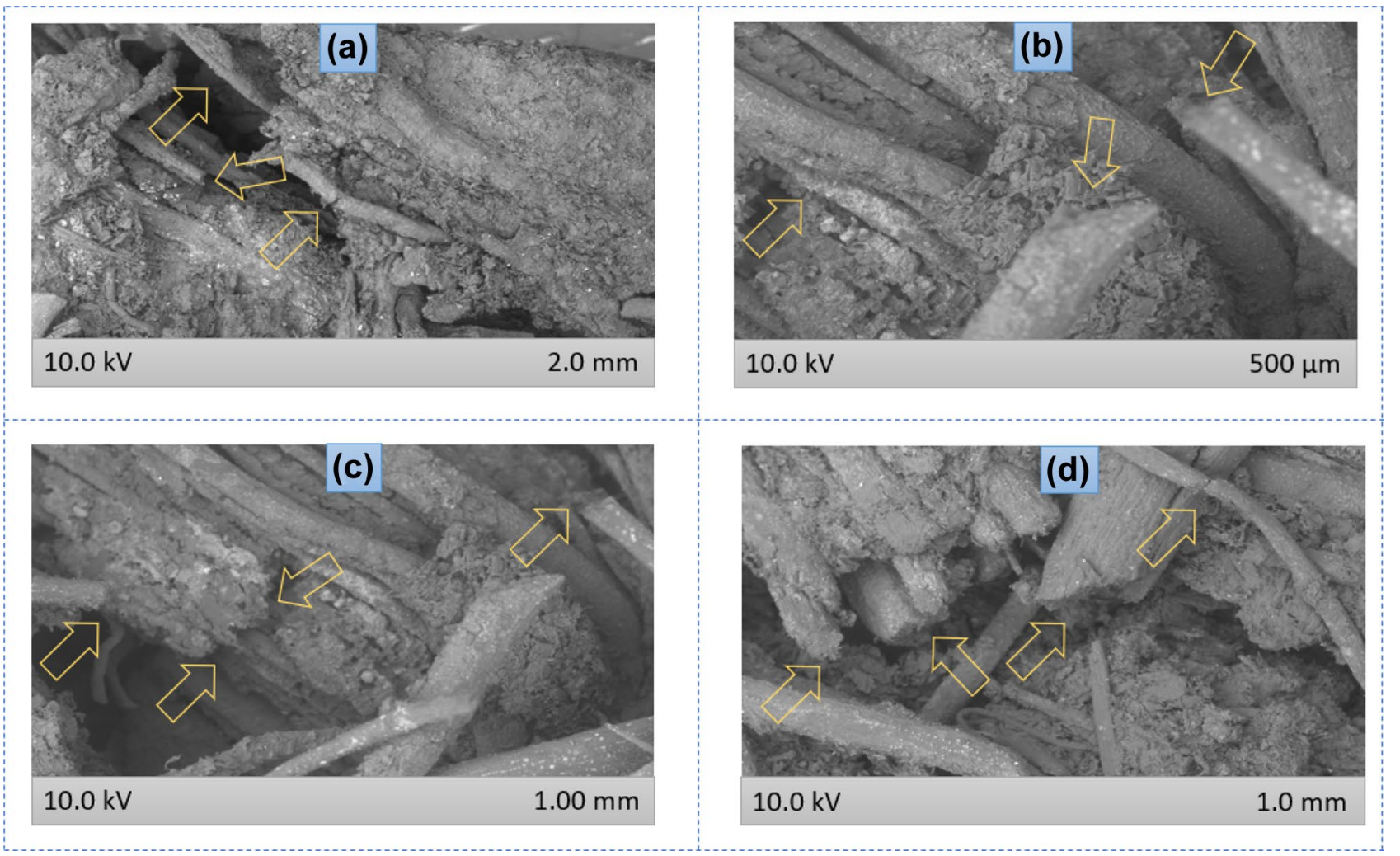

Fig. 5 SEM photographs of test specimens (after fracture) of manufactured composite materials from CSF and CLF materials reinforced with PF resin (a) C@SL1, (b) C@SL2, (c) C@SL3, and (d) C@SL4 

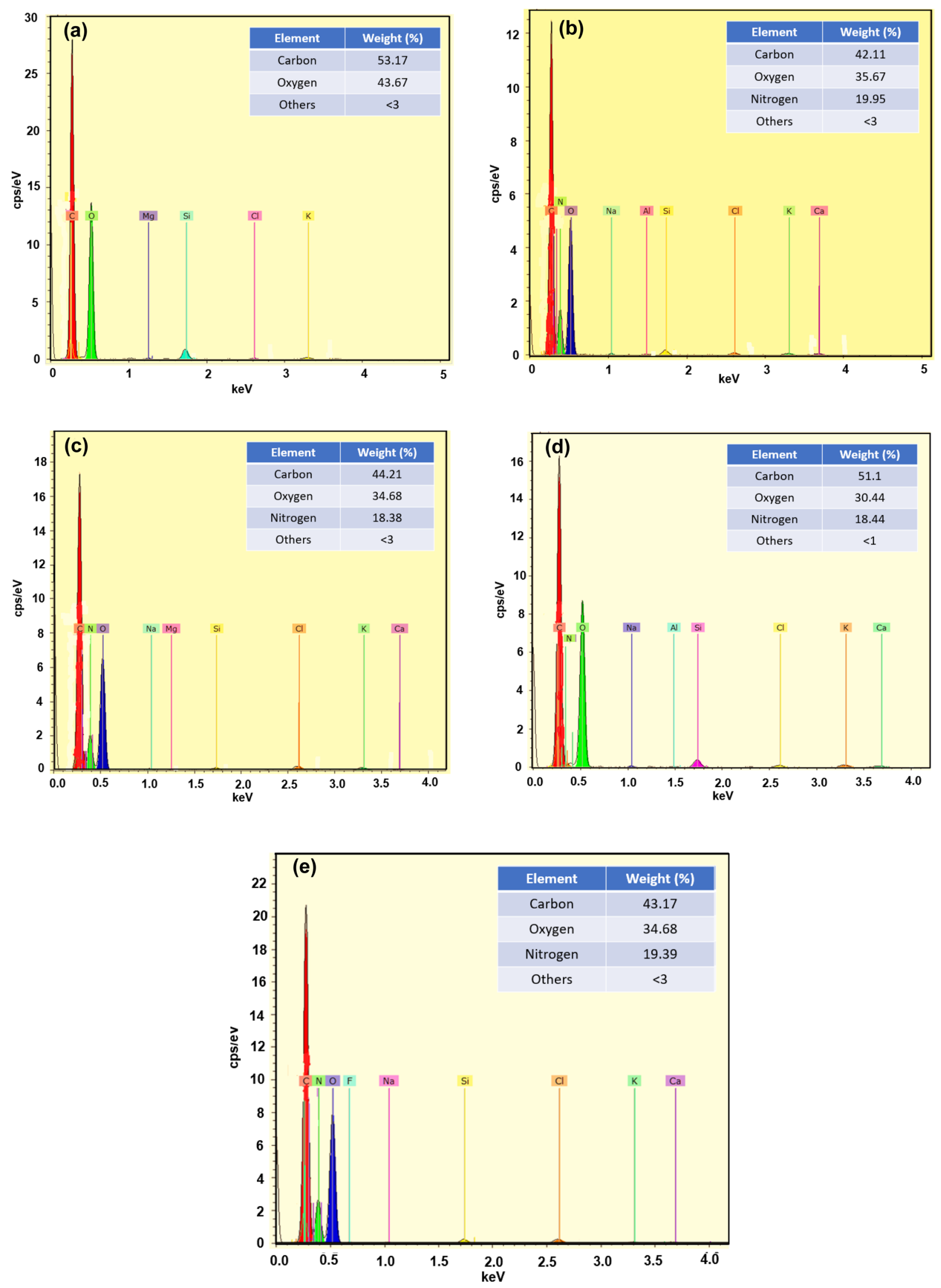
proportions ranging from 18.28\% (C@ @L3) to 19.95\% (C@ SL2). However, the presence of $\mathrm{C}$ and $\mathrm{O}$ are still the highest components present in all cases, although their weight percentage decreased slightly after the reinforcements with $\mathrm{PF}$ resin. The presence of carbon is $53.17 \%$ in the case of the control coir material, which decreased to $42.11 \%$ for C@ SL1, 44.21\% for C@SL2, 51.1\% for C@SL3, and 43.17\% for C@SL4. However, the presence of O also decreased from $43.67 \%$ (control coir) to $35.67 \%$ for C@ SL1, 34.68\% for C@SL2, 30.44\% for C@SL3, and 34.68\% for C@SL4. Conversely, N represents 18.44\% for C@ SL3 and 19.39\% for C@SL4. The overall discussions confirm the successful reinforcement of coir materials with $\mathrm{PF}$ polymeric resins in different densities of composites.

\section{Thermal conductivity of the developed biocomposite panels}

The thermal conductivity of all the composite panels (around $400 \times 400 \times 8 \mathrm{~mm}^{3}$ ) were investigated before the samples were cut for other tests. It is well-known that the lower values of thermal conductivity demonstrate higher insulation properties [50]. Thermal conductivity of phenolic resin is 0.29 to $0.32 \mathrm{Wm}^{-1} \mathrm{k}^{-1}$ in the case of 32 to $64 \mathrm{~kg} / \mathrm{m}^{3}$ density, and it is 0.35 to $0.40 \mathrm{Wm}^{-1} \mathrm{k}^{-1}$ in the case of 112 to $160 \mathrm{~kg} / \mathrm{m}^{3}$ density [51]. Conversely, thermal conductivity of the coir fibers were $0.058 \mathrm{Wm}^{-1} \mathrm{k}^{-1}$ for 30 to $115 \mathrm{~kg} / \mathrm{m}^{3}$ fiber density [52]. However, thermal conductivity observed in this current research for the C@SL4 sample containing the lowest thermal conductivity value by $0.046280(0.000494)$ $\mathrm{Wm}^{-1} \mathrm{k}^{-1}$ indicating the highest insulation property of the material. Conversely, C@SL1 samples provided the highest value of thermal conductivity by $0.062400(0.001146)$ $\mathrm{Wm}^{-1} \mathrm{k}^{-1}$, demonstrating comparatively poor insulation properties compared to other panels. Moreover, composite panels 2 and 3 also provided moderate insulation properties while their thermal conductivity values are 0.062000 (0.000667) and $0.046280(0.000494) \mathrm{Wm}^{-1} \mathrm{k}^{-1}$, respectively. However, all the composite panels provided superior insulation properties for coir fiber reinforced composites

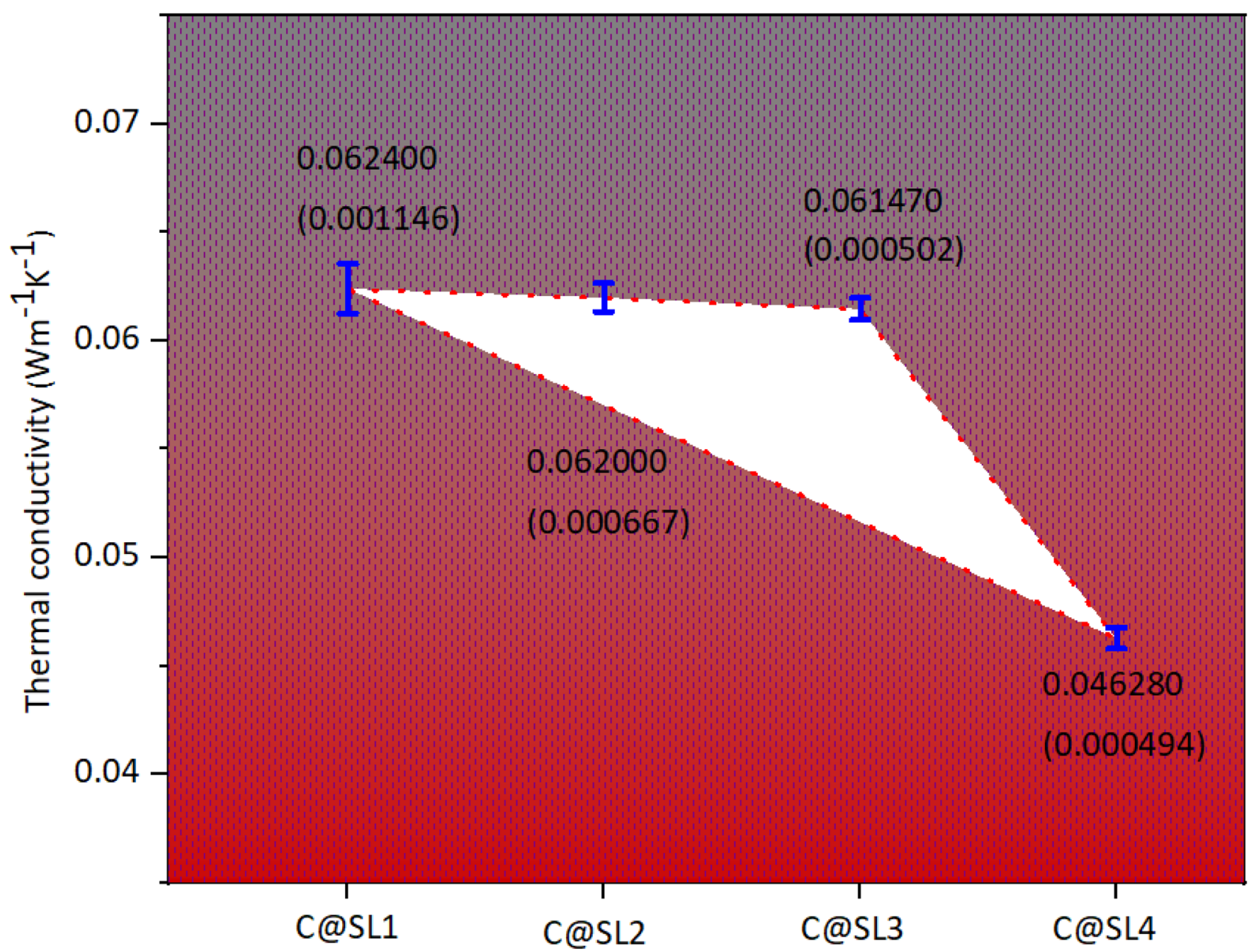

Fig. 7 Thermal conductivity of manufactured composite from CSF and CLF materials reinforced with PF resin 
Fig. 8 FTIR analysis of manufactured composite materials from CSF and CLF material reinforced with $\mathrm{PF}$ resin: (a) control coir material, (b) C@ SL1, (c) C@SL2, (d) C@SL3, and (e) C@ SL4

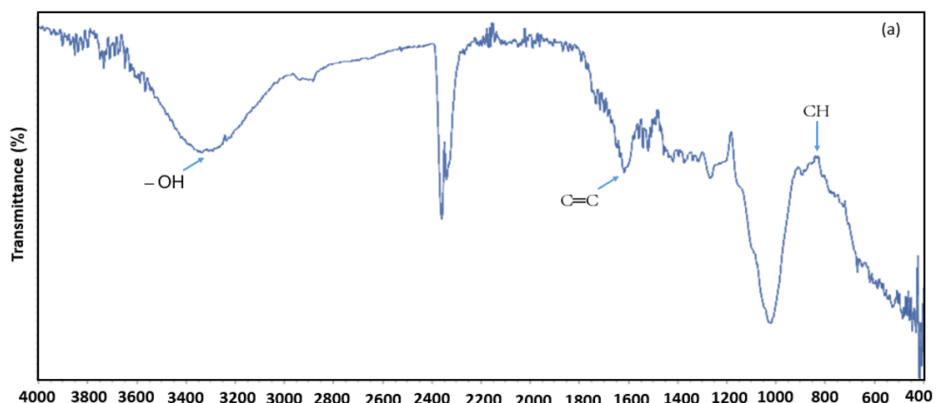

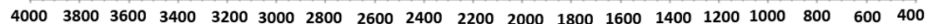
Wavenumber $\left(\mathrm{cm}^{-1}\right)$

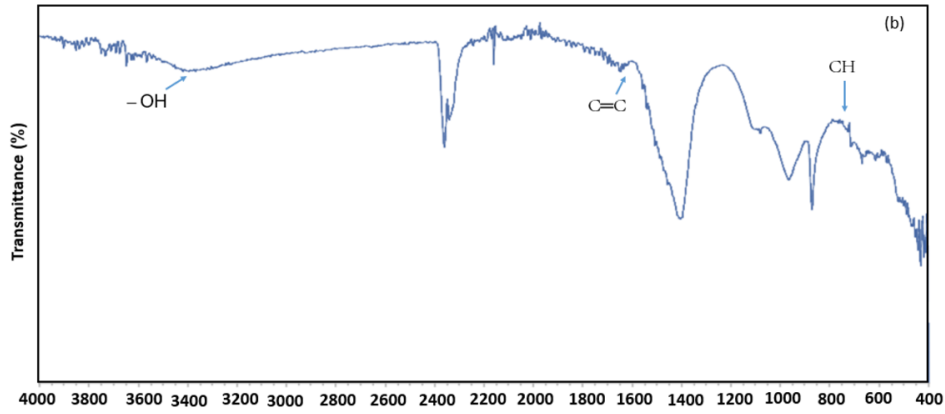
Wavenumber $\left(\mathrm{cm}^{-1}\right)$

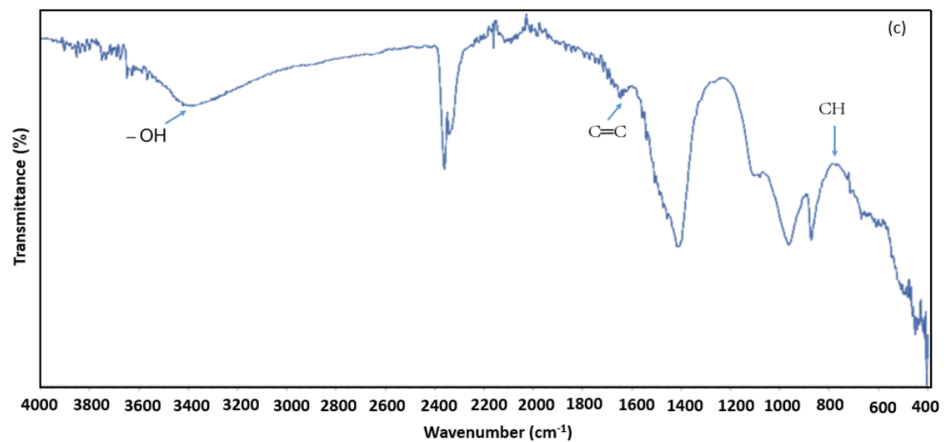
Wavenumber $\left(\mathrm{cm}^{-1}\right)$

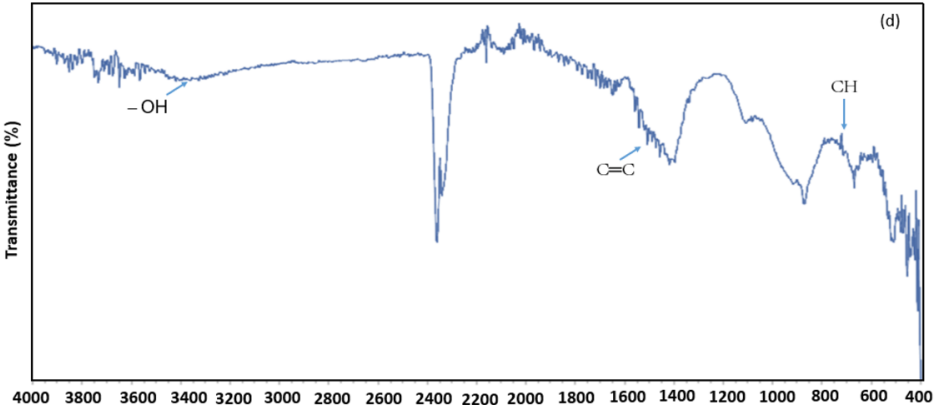
Wavenumber $\left(\mathrm{cm}^{-1}\right)$

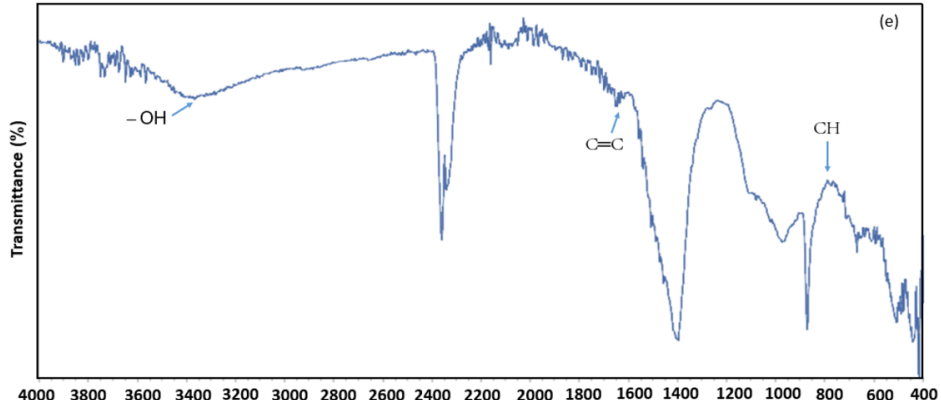

Wavenumber $\left(\mathrm{cm}^{-1}\right)$ 
Table 4 Tabulated results of FTIR peaks in terms of different chemical bonding presence

\begin{tabular}{|c|c|c|c|c|c|}
\hline Test samples & $\begin{array}{l}\text { Control } \\
\text { representing } \\
\text { wavenumbers } \\
\left(\mathrm{cm}^{-1}\right)\end{array}$ & $\begin{array}{l}\text { C@SL1 } \\
\text { representing } \\
\text { wavenumbers } \\
\left(\mathrm{cm}^{-1}\right)\end{array}$ & $\begin{array}{l}\text { C@SL2 } \\
\text { representing } \\
\text { wavenumbers } \\
\left(\mathrm{cm}^{-1}\right)\end{array}$ & $\begin{array}{l}\text { C@SL3 } \\
\text { representing } \\
\text { wavenumbers } \\
\left(\mathrm{cm}^{-1}\right)\end{array}$ & $\begin{array}{l}\text { C@SL4 } \\
\text { representing } \\
\text { wavenumbers } \\
\left(\mathrm{cm}^{-1}\right)\end{array}$ \\
\hline$-\mathrm{OH}$ bond & 3337 & 3396 & 3392 & 3361 & 3396 \\
\hline Aromatic $\mathrm{C}=\mathrm{C}$ bonding & 1616 & 1617 & 1617 & 1617 & 1617 \\
\hline Deformations of alcoholic $\mathrm{C}-\mathrm{H}$ bond & 1419 & 1419 & 1419 & 1419 & 1419 \\
\hline Phenolic resin & 871 & 871 & 872 & 872 & 871 \\
\hline $\begin{array}{l}\text { Carbonyl group and aromatic skeletal } \\
\text { vibrations due to lignin and } \\
\text { hemicellulose [59] }\end{array}$ & 1647 & 1647 & 1647 & 1647 & 1647 \\
\hline
\end{tabular}

(Fig. 7). Furthermore, the density of composite panels varies the distinct thermal conductivity of the panels due to differences in associated densities. In a recent research for coir fiber reinforced panel board, the reported values varied within $0.0547 \pm 0.0004$ to $0.1205 \pm 0.0006 \mathrm{Wm}^{-1} \mathrm{k}^{-1}$ depending on different fiber lengths [53]. In another study for Calotropis procera fiber reinforced composites, the achieved thermal conductivity was within 0.137 to 0.146 $\mathrm{Wm}^{-1} \mathrm{k}^{-1}$ [54]. The overall discussion demonstrates that the perceived thermal conductivity for this current research provided superior insulation properties.

\section{FTIR analysis of developed biocomposite panels}

Moreover, the chemical bonding of the molecules in CSF, CLF, and associated composite panels reinforced with PF resins were also investigated in this current study. The FTIR study is an excellent tool for investigating the formation of covalent bonding, the presence of metallic components, and the detection of functional groups in the materials. The absorption bands appearing at $3368 \mathrm{~cm}^{-1}$ indicate the presence of $-\mathrm{OH}$ bond [55] in the polymeric structure of both coir and other composited materials, demonstrating a strong presence of cellulosic coir materials in the matrix system (Fig. 8). The absorption bands at 1610 $\mathrm{cm}^{-1}$ is related to aromatic $\mathrm{C}=\mathrm{C}$ bonding [56]. However, the peaks after the reinforcements with $\mathrm{PF}$ resin show an upward band compared to the control coir materials. Furthermore, the symmetric and asymmetric deformations of alcoholic $\mathrm{C}-\mathrm{H}$ bond is ascribed by the peaks around $1407 \mathrm{~cm}^{-1}$ [57]. The peak at $1407 \mathrm{~cm}^{-1}$ is most prominent for the materials after PF resin reinforcement due to the assignment of $\mathrm{C}=\mathrm{C}$ benzene ring of phenolic resin [58]. The peaks around $871 \mathrm{~cm}^{-1}$ are related with $\mathrm{CH}$ assignment for isolated $\mathrm{H}$, which is also a characteristic of phenolic resin [58]. Interestingly, the presence of this peak is noticed only for composites materials but absent from control coir. Overall, the FTIR spectrum (Table 4) also demonstrates the strong reinforcement effects of coir materials with the $\mathrm{PF}$ resin.
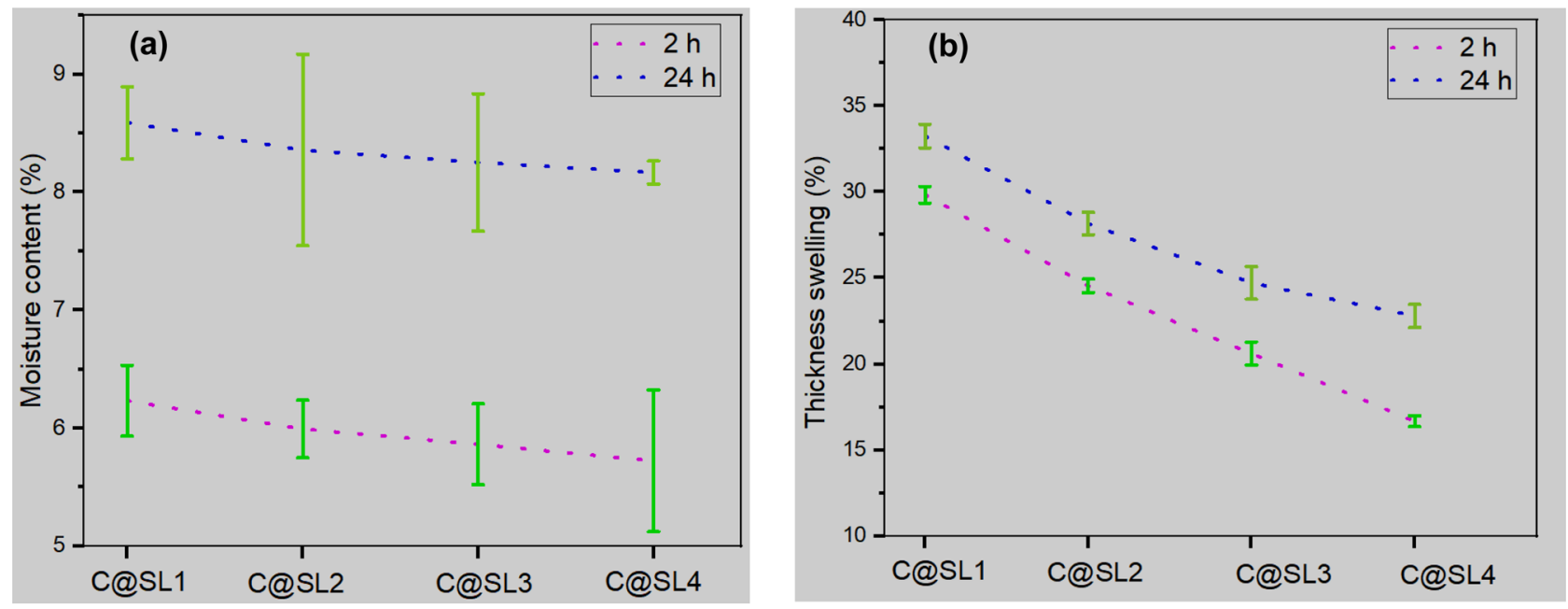

Fig. 9 Physical properties of manufactured composite materials from CSF and CLF reinforced with PF resin: (a) moisture content and (b) thickness swelling 
Fig. 10 TGA analysis of control coir, CSF, and CLF materials reinforced with $P F$ resin composites

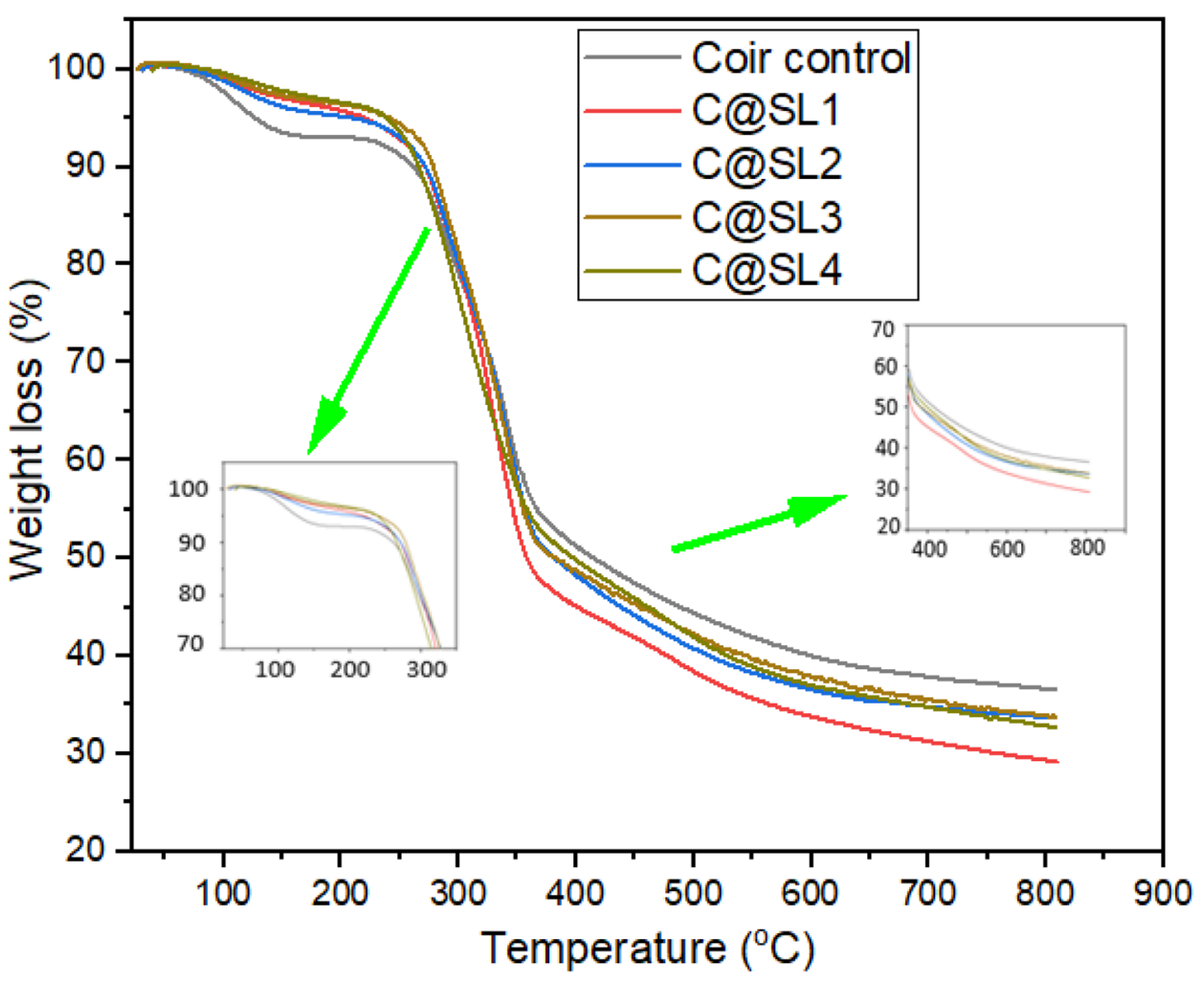

\section{Moisture content and thickness swelling properties of the developed biocomposite panels}

Figure 9 illustrates the moisture content and thickness swelling of the composite panels after $2 \mathrm{~h}$ and $24 \mathrm{~h}$ of water immersion and drying for the same periods. Both moisture content and thickness swelling showed decreasing trends with the increase of density in the composite panels from 360 to $1000 \mathrm{~kg} / \mathrm{m}^{3}$. However, other studies also provided a similar explanation for coir fiber/epoxy composites [60]. Natural lignocellulosic fibers contain $-\mathrm{OH},-\mathrm{COOH}, \mathrm{CO}$, and so on $[61,62]$ in their polymeric structure, which are hydrophilic in nature. Therefore, natural fiber reinforced composite materials also absorb certain amounts of moisture from the atmosphere; hence, the moisture content of the composite materials should be investigated. Moreover, it is also important to check the thickness swelling to ensure the dimensional stability of biocomposites. Composite panel 1 had the highest moisture content values at 6.23 $(0.30)$ and $8.59(0.31) \%$ after 2 and $24 \mathrm{~h}$ of drying, whereas composite panel 4 exhibited the lowest values with 5.72 (0.60)\% and $8.17(0.01) \%$. On the other hand, composite panels 2 and 3 displayed moderate moisture content values. Concerning thickness swelling, composite panel 1 also displayed the highest value $29.83(0.49) \%$ and 33.24 (0.69)\% after 2 and $24 \mathrm{~h}$ of water immersion. The lowest thickness swelling occurred in composite panel 4 as well at $16.68(0.32) \%$ and $22.79(0.65) \%$ for the same duration of time. However, composite panels 2 and 3 also exhibited the thickness swelling range within composite panel 1 and 4. Furthermore, the results discussed here also agree with some previous studies for different natural fiber reinforced composites [63-65]. In summary, it can be concluded that successful reinforcement of CSF and CLF reinforced PF composite panels also significantly influences physical properties, depending on different densities.

\section{TGA analysis of developed biocomposite panels}

Figure 10 presents the thermal stability of multilayered coir fiber reinforced composites. The thermal stability of fabricated hybrid composites from coir materials and PF resin is

Table 5 Tabulated data for control coir, CSF, and CLF materials reinforced with PF resin composites

\begin{tabular}{llll}
\hline Test Samples & $\mathrm{T}_{\text {onset }}\left({ }^{\circ} \mathrm{C}\right)$ & $\mathrm{T}_{\text {Max }}\left({ }^{\circ} \mathrm{C}\right)$ & $\begin{array}{l}\text { Residues/char remaining @ } \\
\text { maximum temperatures of } \\
\text { weight loss }\end{array}$ \\
\hline Control coir & 224 & 800 & 36.78 \\
C@SL1 & 231 & 750 & 30.24 \\
C@SL2 & 231 & 750 & 34.91 \\
C@SL3 & 238 & 750 & 34.28 \\
C@SL4 & 238 & 750 & 33.83 \\
\hline
\end{tabular}


also investigated in terms of TGA, which is responsible for certain factors like moisture absorption rate, heat contraction, and thermal expansion [66]. The degradation behavior of fiber and polymeric matrix in terms of weight loss against certain temperature can easily be quantified using TGA. Some extent of weight loss in the materials due to moisture evaporation was observed at the beginning of heat exposure. Initially, a weight loss (around 3 to $5 \%$ ) is observed around $100{ }^{\circ} \mathrm{C}$ in the case of control coir materials and other composited products [19]. However, noteworthy weight loss is observed within 220 to $300{ }^{\circ} \mathrm{C}$ (Table 5), likely due to the lower proportions of hemicellulose content in coir materials [67]. Moreover, the degradations around 300 to $400{ }^{\circ} \mathrm{C}$ are related with the cellulosic materials [55]. However, after reinforcing the coir fibers with $\mathrm{PF}$ resin, a better resistance against heat exposure is observed for all the cases until 356 ${ }^{\circ} \mathrm{C}$. After that, the composite materials start to degrade more when compared to the control coir materials. The control coir materials had a higher char yield than the composite products. Char yield also shows higher values in higher density panels. This demonstrates that higher density composite materials provide less degradation against temperature.

\section{Conclusions}

The current study developed and reported upon CSF and CLF material reinforced with PF resin composite panel of variable densities with superior insulation properties. Coir chips were defibrated and then sieved before the fabrication into composites. Subsequently, long fibers were cut into $3 \mathrm{~mm}$ lengths before going into composite production. The study produced tri-layered composite panels where the fibers defibrated from chips were used in the core layer and long fibers in the upper and bottom layers in different proportions. The panels were produced by varying the densities from low to medium to high to investigate the reinforcement effects with PF resin in order to attain significant thermal conductivities. The panels demonstrated improved performances with the increase in densities just except the case of high density at $1000 \mathrm{~kg} / \mathrm{m}^{3}$. However, all the medium density composite panels displayed internal bonding strengths higher than $0.6 \mathrm{MPa}$, which meets the requirements of fiberboards in terms of mechanical point of view. The insulation properties of composite panels provided superior performances ranging within $0.0624(0.001146)$ to $0.04628(0.000494)$ $\mathrm{W} /(\mathrm{m} . \mathrm{K})$, with a $25.8 \%$ increase from the lowest to highest densities. The morphological, EDX, and FTIR studies also demonstrate successful reinforcements between the coir materials and PF resin. This current study would be a benchmark for better insulation properties to the composite panel community.
Acknowledgements This work was supported by the "Stipendium Hungaricum" scholarship. Moreover, this article was produced within the framework of "EFOP-3.6.1-16-2016-00018 projects. Authors are also Kun Gábor (University of Sopron) for the cooperation to conduct this research.

Funding Open access funding provided by University of Sopron.

Data availability The datasets needed for reproducing these findings/ used during current research are available from corresponding authors upon reasonable request.

\section{Declarations}

Conflicts of interest The authors declare that they have no conflicts of interest for the submitted work.

Open Access This article is licensed under a Creative Commons Attribution 4.0 International License, which permits use, sharing, adaptation, distribution and reproduction in any medium or format, as long as you give appropriate credit to the original author(s) and the source, provide a link to the Creative Commons licence, and indicate if changes were made. The images or other third party material in this article are included in the article's Creative Commons licence, unless indicated otherwise in a credit line to the material. If material is not included in the article's Creative Commons licence and your intended use is not permitted by statutory regulation or exceeds the permitted use, you will need to obtain permission directly from the copyright holder. To view a copy of this licence, visit http://creativecommons.org/licenses/by/4.0/.

\section{References}

1. Mahmud S et al (2021) Comprehensive review on plant fiberreinforced polymeric biocomposites. J Mater Sci 56:7231-7264

2. Hasan KF, Horváth PG, Kóczán Z, Bak M, Alpár T (2021) Nanotechnology for waste wood recycling, in Nanotechnology in Paper and Wood Engineering. Woodhead Publishing: Duxford, United Kingdom

3. Hasan KF, Horváth PG, Zsolt K, Alpár T (2021) Design and fabrication technology in biocomposite manufacturing, in Toward the value-added biocomposites: technology, innovation and opportunity. CRC Press: Boca Raton, USA

4. Hasan KF, Horváth PG, Zsolt K, Alpár T (2021) Introduction to biomass and biocomposites, in Toward the value-added biocomposites: technology, innovation and opportunity. CRC Press: Boca Raton, USA

5. Ramamoorthy SK, Skrifvars M, Persson A (2015) A review of natural fibers used in biocomposites: plant, animal and regenerated cellulose fibers. Polym Rev 55(1):107-162

6. Li M et al (2020) Recent advancements of plant-based natural fiber-reinforced composites and their applications. Compos Part B Eng 200:108254

7. Latif R et al (2019) Surface treatments of plant fibers and their effects on mechanical properties of fiber-reinforced composites: A review. J Reinf Plast Compos 38(1):15-30

8. Hasan KF, Horváth PG, Alpár T (2021) Silk protein and its nanocomposites. In Biopolym Nanomater: Fundament Appl Elsevier p 309-323. https://doi.org/10.1016/B978-0-12-824364-0.00027-7

9. Hasan K, Horváth PG, Alpár T (2021) Potential fabricreinforced composites: a comprehensive review. J Mater Sci 56:14381-14415 
10. Ayrilmis $\mathrm{N}$ et al (2011) Coir fiber reinforced polypropylene composite panel for automotive interior applications. Fibers Polym 12(7):919-926

11. Javadi A et al (2010) Processing and characterization of solid and microcellular PHBV/coir fiber composites. Mater Sci Eng C 30(5):749-757

12. Nam TH et al (2011) Effect of alkali treatment on interfacial and mechanical properties of coir fiber reinforced poly (butylene succinate) biodegradable composites. Compos Part B Eng 42(6): 1648-1656

13. Surin P et al (2015) Effects of coir fiber and maleic anhydride modification on the properties of thermoplastic starch/PLA composite laminates. J Nat Fibers 12(2):108-120

14. Sultana MZ et al (2019) Green synthesis of glycerol monostearatemodified cationic waterborne polyurethane. Emerg Mater Res $8(2): 137-147$

15. Biswas S, Kindo S, Patnaik A (2011) Effect of fiber length on mechanical behavior of coir fiber reinforced epoxy composites. Fibers Polym 12(1):73-78

16. Romli FI et al (2012) Factorial study on the tensile strength of a coir fiber-reinforced epoxy composite. AASRI Proc 3:242-247

17. Ferraz JM et al (2011) Effects of treatment of coir fiber and cement/fiber ratio on properties of cement-bonded composites. BioResources 6(3):3481-3492

18. Andiç-Çakir Ö et al (2014) Physical and mechanical properties of randomly oriented coir fiber-cementitious composites. Compos Part B Eng 61:49-54

19. Nam TH, Ogihara S, Kobayashi S (2012) Interfacial, mechanical and thermal properties of coir fiber-reinforced poly (lactic acid) biodegradable composites. Adv Compos Mater 21(1):103-122

20. Hasan KF et al (2021) Semi-dry technology-mediated coir fiber and Scots pine particle-reinforced sustainable cementitious composite panels. Constr Build Mater 305:124816

21. Tan C et al (2021) Development of coir-fiber-reinforced nanocomposite for shell eco marathon vehicle body application. Mater Today: Proceed

22. Arshad MN et al (2021) Effect of coir fiber and TiC nanoparticles on basalt fiber reinforced epoxy hybrid composites: Physicomechanical characteristics. Cellulose 28(6):3451-3471

23. Hasan $\mathrm{KF}$ et al (2021) Hemp/glass woven fabric reinforced laminated nanocomposites via in-situ synthesized silver nanoparticles from Tilia cordata leaf extract. Compos Interfaces

24. Hasan KF et al (2021) Thermo-mechanical properties of pretreated coir fiber and fibrous chips reinforced multilayered composites. Sci Rep 11(1):1-13

25. Hasan KMF, Horváth PG, Alpár T (2020) Potential natural fiber polymeric nanobiocomposites: A review. Polymers 12(5):1-25

26. Hasan KF et al (2021) A state-of-the-art review on coir fiberreinforced biocomposites. RSC Adv 11(18):10548-10571

27. Li Z, Wang L, Wang X (2006) Flexural characteristics of coir fiber reinforced cementitious composites. Fibers Polym 7(3):286-294

28. Gupta N, Ramkumar P (2021) Effect of coir content on mechanical and thermal properties of LLDPE/coir blend processed by rotational molding. Sādhanā 46(1):1-12

29. Thamaraiselvan V, Mekala N, Dhanapriya G (2021) Development of acoustic absorption composite with application of coir and viscose. IOP Conf Ser: Mater Sci Eng 1059(1):012028

30. Guna V et al (2021) Wool and coir fiber reinforced gypsum ceiling tiles with enhanced stability and acoustic and thermal resistance. J Build Eng 102433

31. Thakur VK, Thakur MK (2014) Processing and characterization of natural cellulose fibers/thermoset polymer composites. Carbohydr Polym 109:102-117
32. Adesina $\mathrm{O}$ et al (2019) Mechanical evaluation of hybrid natural fibre-reinforced polymeric composites for automotive bumper beam: a review. Int J Adv Manuf Technol 103(5):1781-1797

33. Kumar SS (2020) Dataset on mechanical properties of natural fiber reinforced polyester composites for engineering applications. Data Brief 28:105054

34. Gallos A et al (2017) Lignocellulosic fibers: a critical review of the extrusion process for enhancement of the properties of natural fiber composites. RSC Adv 7(55):34638-34654

35. Premnath AA (2018) Impact of surface treatment on the mechanical properties of sisal and jute reinforced with epoxy resin natural fiber hybrid composites. J Nat Fibers 16(5):718-728

36. Kumar S et al (2019) Himalayan natural fiber-reinforced epoxy composites: effect of Grewia optiva/Bauhinia Vahlii fibers on physico-mechanical and dry sliding wear behavior. J Nat Fibers 18(2):192-202

37. Hasan KMF, Péter György H, Tibor A (2020) Thermomechanical Behavior of Methylene Diphenyl Diisocyanate-Bonded Flax/ Glass Woven Fabric Reinforced Laminated Composites. ACS Omega 6(9):6124-6133

38. Bharath K et al (2019) Effect of stacking sequence on properties of coconut leaf sheath/jute/E-glass reinforced phenol formaldehyde hybrid composites. J Ind Text 49(1):3-32

39. Maya M et al (2017) Mechanical properties of short sisal fibre reinforced phenol formaldehyde eco-friendly composites. Polym Renew Res 8(1):27-42

40. Barbosa V Jr et al (2010) Biobased composites from tanninphenolic polymers reinforced with coir fibers. Ind Crops Prod 32(3):305-312

41. Malkapuram R, Kumar V, Negi YS (2009) Recent development in natural fiber reinforced polypropylene composites. J Reinf Plast Compos 28(10):1169-1189

42. Hasan KF, Horváth PG, Alpár T (2021) Development of lignocellulosic fiber reinforced cement composite panels using semidry technology. Cellulose 28:3631-3645

43. Hasan KMF, Horváth PG, Alpár T (2021) Development of lignocellulosic fiber reinforced cement composite panels using semi-dry technology. Cellulose 28(6):3631-3645

44. Hasan KF et al (2021) Rice straw and energy reeds fiber reinforced phenol formaldehyde resin hybrid polymeric composite panels. Cellulose

45. Yan L et al (2016) Effect of alkali treatment on microstructure and mechanical properties of coir fibres, coir fibre reinforced-polymer composites and reinforced-cementitious composites. Constr Build Mater 112:168-182

46. Jayabal $\mathrm{S}$ et al (2013) Mechanical and machinability behaviors of woven coir fiber-reinforced polyester composite. Fibers Polym 14(9): 1505-1514

47. dos Santos JC et al (2018) Effects of sodium carbonate on the performance of epoxy and polyester coir-reinforced composites. Polym Test 67:533-544

48. Suresh S, Sudhakara D, Vinod B (2020) Investigation on industrial waste eco-friendly natural fiber-reinforced polymer composites. J Bio-and Tribo-Corrosion 6(2):1-14

49. Rout J et al (2003) SEM observations of the fractured surfaces of coir composites. J Reinf Plast Compos 22(12):1083-1100

50. Ma Y, Wang C, Chu F (2017) Effects of Fiber Surface Treatments on the Properties of Wood Fiber-Phenolic Foam Composites. BioResources 12(3):4722-4736

51. Yang Y (2007) Thermal Conductivity. In: Mark JE (ed) Physical properties of polymers handbook. Springer, New York, USA, pp $155-164$

52. Kochhar GS, Manohar K (1997) Use of coconut fiber as a low-cost thermal insulator, in insulation materials: testing and applications, 3rd volume. ASTM Int p 283-291 
53. Asasutjarit C et al (2007) Development of coconut coir-based lightweight cement board. Constr Build Mater 21(2):277-288

54. Yoganandam K et al (2019) Thermogravimetric analysis of Calotropis procera fibers and their influence on the thermal conductivity and flammability studies of polymer composites. Mater Res Expr 6(10): 105341

55. Kumar SS, Duraibabu DA, Subramanian K (2014) Studies on mechanical, thermal and dynamic mechanical properties of untreated (raw) and treated coconut sheath fiber reinforced epoxy composites. Mater Des 59:63-69

56. Laili Z, Omar M, Yasir MS, Ibrahim MZ, Yahaya MY, Murshidi JA (2010) Instrumental characterization of coir pith by XRD, FTIR and SEM after radium adsorption from aqueous solution under the presence of humic acids. in AIP Conference Proceedings. Am Inst Phys

57. Verma D, Gope P (2015) The use of coir/coconut fibers as reinforcements in composites. Biofiber Reinforcements in Composite Materials. Woodhead Publishing, Duxford, United Kingdom, pp 285-319

58. Holopainen T et al (1998) J Appl Polym Sci 69(11):21752185. https://doi.org/10.1002/(SICI)1097-4628(19980912)69:11

59. Abraham E et al (2013) Environmental friendly method for the extraction of coir fibre and isolation of nanofibre. Carbohydr Polym 92(2):1477-1483

60. Das G, Biswas S (2016) Physical, mechanical and water absorption behaviour of coir fiber reinforced epoxy composites filled with $\mathrm{Al}_{2} \mathrm{O}_{3}$ particulates. IOP Conf Ser Mater Sci Eng 115(1):012012

61. Hasan KF, Horváth PG, Alpár T (2021) Lignocellulosic fiber cement compatibility: A state of the art review. J Nat Fibers 1-26
62. Hasan KF, Horvath PtGr, Alpar T (2021) Thermomechanical Behavior of Methylene Diphenyl Diisocyanate-Bonded Flax/Glass Woven Fabric Reinforced Laminated Composites. ACS Omega 6(9):6124-6133

63. Balaji A et al (2019) Study on mechanical and morphological properties of sisal/banana/coir fiber-reinforced hybrid polymer composites. J Brazilian Soc Mech Sci Eng 41(9):1-10

64. Saw SK et al (2014) Hybrid composites made from jute/coir fibers: Water absorption, thickness swelling, density, morphology, and mechanical properties. J Nat Fibers 11(1):39-53

65. Jawaid $\mathrm{M}$ et al (2011) Hybrid composites made from oil palm empty fruit bunches/jute fibres: Water absorption, thickness swelling and density behaviours. J Polym Environ 19(1):106-109

66. Singh Y et al (2020) Fabrication and characterization of coir/ carbon-fiber reinforced epoxy based hybrid composite for helmet shells and sports-good applications: influence of fiber surface modifications on the mechanical, thermal and morphological properties. J Mater Res Technol 9(6):15593-15603

67. Hasan KF, Horváth PG, Kóczán Z, Alpár T (2021) Thermo-mechanical properties of pretreated coir fiber and fibrous chips reinforced multilayered composites. Sci Rep 1-13

Publisher's Note Springer Nature remains neutral with regard to jurisdictional claims in published maps and institutional affiliations. 